Jpn. J. Genet. (1988) 63, pp. 413-423

\title{
A cytological study of Podocarpus macrophyllus with special reference to sex chromosomes
}

\author{
Masahiro Hizume, Hiroto Shiraishi and Akio Tanaka \\ Biological Institute, Faculty of Education, \\ Ehime University, Matsuyama 790
}

(Received June 17, 1988)

\begin{abstract}
Female and male plants of Podocarpus macrophyllus (Thunb.) Lamb. were cytologically investigated. The chromosome numbers were $2 n=38$ in the female plants, and $2 n=37$ in the male plants. The chromosome complement in female was composed of 38 telocentric chromosomes, and that in male was composed of one large submetacentric chromosome and 36 telocentric chromosomes. Bright chromomycin $\mathrm{A}_{3}$ bands appeared at the proximally interstitial region of two middle-sized telocentric chromosomes in both the female and male plants and coincided with secondary constriction in position. DAPI-bands appeared at proximal regions of about two-third the large telocentric chromosomes, but did not in the large submetacentric chromosome and the small telocentric chromosomes. Seventeen bivalents and one trivalent were constantly formed at meiotic metaphase $I$ in the pollen mother cells (PMCs). The trivalent displayed a conspicuous shape with one free chromosomal end. These chromosomes were segregated into an anaphase I group of $n=18$ with a large submetacentric chromosome, and the other anaphase I group of $n=19$. These observations on mitotic and meiotic chromosomes strongly suggest that sex of $P$. macrophyllus could be determined by the XXY type of the sex chromosome system.
\end{abstract}

\section{INTRODUCTION}

The majority of the species of the genus Podocarpus is distributed throughout the temperate to tropical zones in the Southern Hemisphere. The genus might be originated in the Southern Hemisphere in early Mesozoic era, and expanded the habitat into the Northern Hemisphere in the Quaternary era (Florin, 1963). Podocarpus macrophyllus (Thunb.) Lamb. is one of the northern species and has the northmost distribution in Tottori, the Honsyu island, Japan (latitude $35^{\circ} 33^{\prime}$; Hayashi, 1960). This species is strictly dioecious.

The chromosome number of $P$. macrophyllus and its variety ( $P$. macrophyllus var. maki Sieb.) was first reported to be $2 n=38-40$ (Flory, 1936), but later to be $n=19$ and $2 n=38$ (Tahara, 1941; Mehra and Khoshoo, 1956). Mehra and Khoshoo (1956) reported that most of the members of the chromosome complement had centromeres at their subterminal or terminal regions and showed differences in size. However, the karyotype of this species has not been analyzed in detail, and any sex chromosome has not been detected in this species and any other dioecious 
species of Podocarpus.

This paper reveals the karyotypes of the female and the male plants of $P$. macrophyllus, and the meiotic behavior of chromosomes in PMCs. The presence of the sex chromosomes is discussed.

\section{MATERIALS AND METHODS}

Cutting scions of female and male trees of Podocarpus macrophyllus (Thunb.) Lamb. were collected from 13 localities tabulated in Table 1, and they were rooted in moistened soil for about two months. Thirty female clones, 41 male clones, and four clones of unknown sex were cytologically studied.

Table 1. Locality, number of plants and chromosome number of Podocarpus macrophyllus examined

\begin{tabular}{|c|c|c|c|c|c|}
\hline \multirow{2}{*}{ Locality } & \multicolumn{2}{|c|}{$\begin{array}{c}\text { Number of } \\
\text { plants }\end{array}$} & \multicolumn{3}{|c|}{$\begin{array}{l}\text { Chromosome } \\
\text { number }(2 n)\end{array}$} \\
\hline & female & male & female & & male \\
\hline Kamigamo, Kyoto, Kyoto Pref. & & 1 & & & 37 \\
\hline Bunkyocho, Matsuyama, Ehime Pref. & 17 & 20 & 38 & & 37 \\
\hline Iwaidani, Matsuyama, Ehime Pref. & 4 & 6 & 38 & & 37 \\
\hline Dogo, Matsuyama, Ehime Pref. & 2 & 2 & 38 & & 37 \\
\hline Dogohimata, Matsuyama, Ehime Pref. & 4 & 2 & 38 & & 37 \\
\hline Tobe, Matsuyama, Ehime Pref. & 2 & & 38 & & \\
\hline Himebara, Matsuyama, Ehime Pref. & & 2 & & & 37 \\
\hline Tosayamada, Kochi Pref. & 3 & 4 & 38 & & 37 \\
\hline Shuri, Naha, Okinawa Pref. & & 1 & & 38 & 37 \\
\hline Aha, Kunigami, Okinawa Pref. & & & & 37 & \\
\hline Urauchikawa, Iriomote, Okinawa Pref. & & 1 & & 38 & 37 \\
\hline Takahishi, Iriomote, Okinawa Pref. & 1 & 1 & 38 & & 37 \\
\hline Omoto, Ishigaki, Okinawa Pref. & & 1 & & & $37+7 B$ \\
\hline
\end{tabular}

* Sex not determined.

Root tips and shoot apices were collected and treated with $0.05 \%$ colchicine at $20^{\circ} \mathrm{C}$ for about $6 \mathrm{~h}$ and fixed in 1:3 acetic alcohol at $4^{\circ} \mathrm{C}$ overnight. After fixation they were macerated in a $2: 1$ mixture of $1 \mathrm{~N} \mathrm{HCl}$ and $45 \%$ acetic acid at $60^{\circ} \mathrm{C}$ for 10 sec. Meristematic tissues in the root tips and the shoot apices were isolated on glass slides, and were stained and squashed in $2 \%$ aceto-orcein. The fluorescent staining with chromomycin $\mathrm{A}_{3}$ (CMA) and 4',6-diamidino-2-phenylindole (DAPI) followed Kondo and Hizume (1982). Male strobili were collected in May, 1982-1987, and fixed in the fixative of 1:3 acetic alcohol. PMCs were smeared on glass slides, and then stained with $1 \%$ aceto-orcein for observation of meiosis. 


\section{RESULTS}

\section{Karyotypes of female and male plants}

The chromosomes at interphase diffused homogeneously as fibrous chromatins and many small chromomeres, and some chromosomes formed several heteropycnotic bodies leaned to one side of the nucleus (Fig. 1A, C). Proximal regions of most of the chromosomes condensed at early prophase, earlier than the other regions did (Fig. 1B, D). Distribution patterns of the chromosomes at interphase, and condensation of the chromosomes at prophase were both very similar in female and male.

The chromosome number was $2 n=38$ in the female plants (Fig. 2A, B), and $2 n=37$ in the male plants (Fig. 2C, D). One male plant had seven small supernumerary chromosomes $(2 n=37+7 \mathrm{~B})$. All chromosomes of the metaphase complement in the female plants were telocentric (Fig. 3A), and 2.0 to $7.5 \mu \mathrm{m}$ in length (Table 2). A pair of the largest chromosomes was discontinuously much longer than the other chromosomes. A pair of middle-sized chromosomes (the 10th pair) had a secondary constriction at the proximally interstitial region. In contrast, the metaphase chromosome complement of the male plants $(2 n=37)$ was composed of a prominent, large submetacentric chromosome of $9.1 \mu \mathrm{m}$ long and 36 telocentric chromosomes (Table 3, Fig. 3B). The largest telocentric chromosome

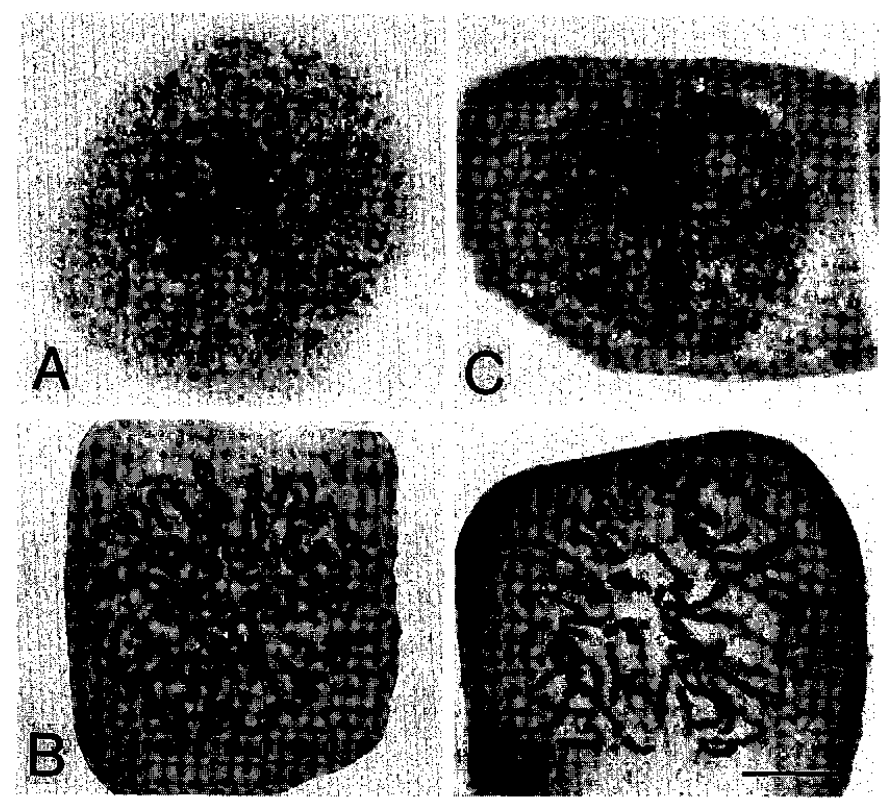

Fig. 1. Interphase nuclei and chromosomes at mitotic prophase in Podocarpus macrophyllus. A; an interphase nucleus of a female plant, B; chromosomes at prophase of a female plant, $\mathrm{C}$; an interphase nucleus of a male plant, D; chromosomes at prophase of a male plant. Bar represents $10 \mu \mathrm{m}$. 

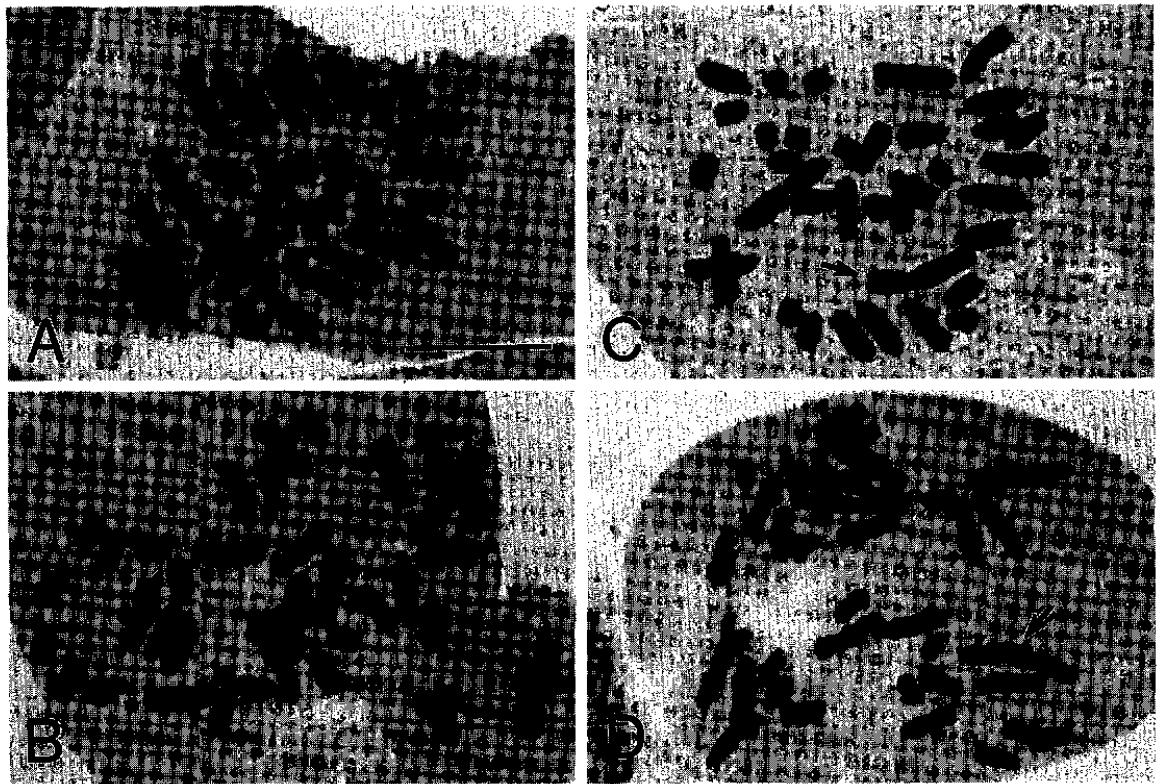

Fig. 2. Somatic chromosomes at metaphase in $P$. macrophyllus. A and B; in female plants $(2 n=38)$, $\mathrm{C}$ and $\mathrm{D}$; in male plants $(2 n=37)$. Arrows point submetacentric chromosomes. Bar represents 10 $\mu \mathrm{m}$.

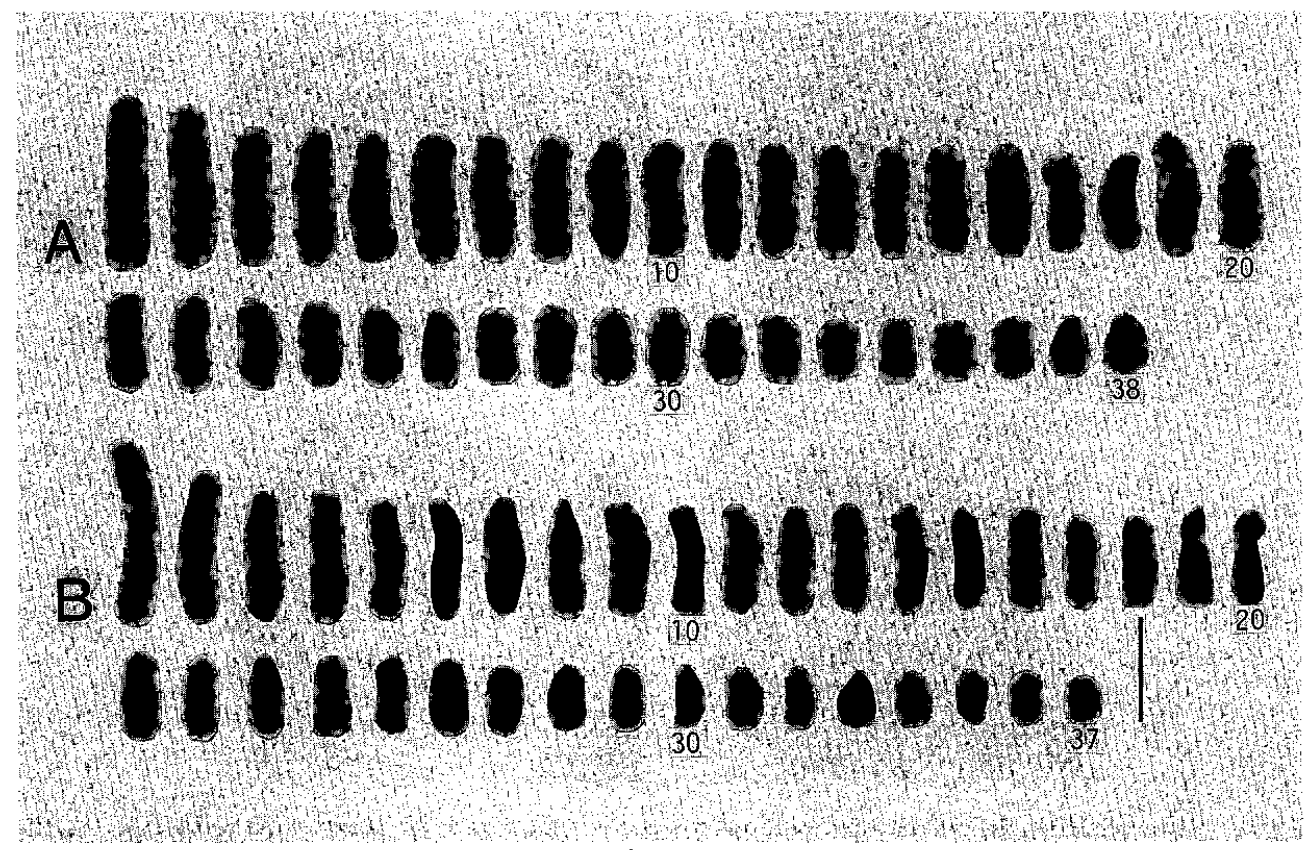

Fig. 3. Somatic metaphase chromosomes of $P$. macrophyllus arranged in the order of length. A; in a female plant $(2 n=38), \mathrm{B}$; in a male plant $(2 n=37)$. Bar represents $5 \mu \mathrm{m}$. 
Table 2. Measurements of metaphase chromosomes in female plant of Podocarpus macrophyllus

\begin{tabular}{|c|c|c|c|c|c|c|}
\hline \multirow{2}{*}{ Chromosome } & \multicolumn{3}{|c|}{ Length $(\mu \mathrm{m})$} & \multirow{2}{*}{$\begin{array}{l}\text { Relative } \\
\text { length }\end{array}$} & \multirow{2}{*}{$\begin{array}{l}\text { Arm } \\
\text { ratio }\end{array}$} & \multirow{2}{*}{ Form } \\
\hline & Long arm & Short arm & Total & & & \\
\hline 1 & 7.5 & 0 & 7.5 & 4.9 & - & $\mathbf{t}$ \\
\hline 2 & 7.2 & 0 & 7.2 & 4.7 & - & $\mathbf{t}$ \\
\hline 3 & 6.3 & 0 & 6.3 & 4.1 & - & $\mathbf{t}$ \\
\hline 4 & 6.0 & 0 & 6.0 & 3.9 & - & $\mathrm{t}$ \\
\hline 5 & 5.7 & 0 & 5.7 & 3.7 & - & $\mathbf{t}$ \\
\hline 6 & 5.6 & 0 & 5.6 & 3.6 & - & $\mathrm{t}$ \\
\hline 7 & 5.4 & 0 & 5.4 & 3.5 & - & $\mathbf{t}$ \\
\hline 8 & 5.3 & 0 & 5.3 & 3.4 & - & $\mathbf{t}$ \\
\hline 9 & 5.1 & 0 & 5.1 & 3.3 & - & $\mathbf{t}$ \\
\hline 10 & 5.1 & 0 & 5.1 & 3.3 & - & $\mathrm{t}$ \\
\hline 11 & 5.0 & 0 & 5.0 & 3.2 & - & $\mathbf{t}$ \\
\hline 12 & 4.9 & 0 & 4.9 & 3.2 & - & $\mathrm{t}$ \\
\hline 13 & 4.8 & 0 & 4.8 & 3.1 & - & $\mathrm{t}$ \\
\hline 14 & 4.6 & 0 & 4.6 & 3.0 & - & $t$ \\
\hline 15 & 4.5 & 0 & 4.5 & 2.9 & - & $\mathrm{t}$ \\
\hline 16 & 4.4 & 0 & 4.4 & 2.8 & - & $\mathbf{t}$ \\
\hline 17 & 4.3 & 0 & 4.3 & 2.8 & - & $\mathrm{t}$ \\
\hline 18 & 4.1 & 0 & 4.1 & 2.7 & - & $t$ \\
\hline 19 & $4.0^{*}$ & 0 & 4.0 & 2.6 & - & $\mathbf{t}$ \\
\hline 20 & $3.9^{*}$ & 0 & 3.9 & 2.5 & - & $\mathbf{t}$ \\
\hline 21 & 3.9 & 0 & 3.9 & 2.5 & - & $\mathrm{t}$ \\
\hline 22 & 3.7 & 0 & 3.7 & 2.4 & - & $\mathbf{t}$ \\
\hline 23 & 3.6 & 0 & 3.6 & 2.3 & - & $\mathbf{t}$ \\
\hline 24 & 3.4 & 0 & 3.4 & 2.2 & - & $\mathbf{t}$ \\
\hline 25 & 3.3 & 0 & 3.3 & 2.1 & - & $t$ \\
\hline 26 & 3.1 & 0 & 3.1 & 2.0 & - & $t$ \\
\hline 27 & 3.0 & 0 & 3.0 & 1.9 & - & $t$ \\
\hline 28 & 2.9 & 0 & 2.9 & 1.9 & - & $\mathbf{t}$ \\
\hline 29 & 2.8 & 0 & 2.8 & 1.8 & - & $\mathbf{t}$ \\
\hline 30 & 2.7 & 0 & 2.7 & 1.7 & - & $t$ \\
\hline 31 & 2.6 & 0 & 2.6 & 1.7 & - & $\mathbf{t}$ \\
\hline 32 & 2.5 & 0 & 2.5 & 1.6 & - & $\mathrm{t}$ \\
\hline 33 & 2.4 & 0 & 2.4 & 1.6 & - & $\mathrm{t}$ \\
\hline 34 & 2.3 & 0 & 2.3 & 1.5 & - & $\mathrm{t}$ \\
\hline 35 & 2.3 & 0 & 2.3 & 1.5 & - & $t$ \\
\hline 36 & 2.2 & 0 & 2.2 & 1.4 & - & $\mathrm{t}$ \\
\hline 37 & 2.1 & 0 & 2.1 & 1.4 & - & $\mathrm{t}$ \\
\hline 38 & 2.0 & 0 & 2.0 & 1.3 & - & $\mathrm{t}$ \\
\hline
\end{tabular}

* With a secondary constriction. Each value is the mean of 15 metaphase complements in eight different plants. 
Table 3. Measurements of metaphase chromosomes in male plant of Podocarpus macrophyllus

\begin{tabular}{|c|c|c|c|c|c|c|}
\hline \multirow{2}{*}{ Chromosome } & \multicolumn{3}{|c|}{ Length $(\mu \mathrm{m})$} & \multirow{2}{*}{$\begin{array}{l}\text { Relative } \\
\text { length }\end{array}$} & \multirow{2}{*}{$\begin{array}{l}\text { Arm } \\
\text { ratio }\end{array}$} & \multirow{2}{*}{ Form } \\
\hline & Long arm & Short arm & Total & & & \\
\hline 1 & 5.8 & 3.3 & 9.1 & 6.2 & 1.8 & sm \\
\hline 2 & 6.8 & 0 & 6.8 & 4.6 & - & $\mathrm{t}$ \\
\hline $\mathbf{3}$ & 5.9 & 0 & 5.9 & 4.0 & - & $\mathbf{t}$ \\
\hline 4 & 5.7 & $\mathbf{0}$ & 5.7 & 3.9 & - & $\mathbf{t}$ \\
\hline 5 & 5.5 & 0 & 5.5 & 3.7 & - & $\mathbf{t}$ \\
\hline 6 & 5.3 & 0 & 5.3 & 3.6 & - & $\mathbf{t}$ \\
\hline 7 & 5.2 & 0 & 5.2 & 3.5 & - & $\mathbf{t}$ \\
\hline 8 & 5.1 & 0 & 5.1 & 3.5 & - & $\mathbf{t}$ \\
\hline 9 & 5.0 & 0 & 5.0 & 3.4 & - & $\mathbf{t}$ \\
\hline 10 & 4.9 & 0 & 4.9 & 3.3 & - & $\mathbf{t}$ \\
\hline 11 & 4.8 & 0 & 4.8 & 3.3 & - & $\mathbf{t}$ \\
\hline 12 & 4.7 & 0 & 4.7 & 3.2 & - & $\mathbf{t}$ \\
\hline 13 & 4.7 & 0 & 4.7 & 3.2 & - & $\mathbf{t}$ \\
\hline 14 & 4.5 & 0 & 4.5 & 3.1 & - & $t$ \\
\hline 15 & 4.5 & 0 & 4.5 & 3.1 & - & $\mathbf{t}$ \\
\hline 16 & 4.2 & 0 & 4.2 & 2.8 & - & $\mathbf{t}$ \\
\hline 17 & 4.1 & 0 & 4.1 & 2.8 & - & $t$ \\
\hline 18 & 4.0 & 0 & 4.0 & 2.7 & - & $\mathrm{t}$ \\
\hline 19 & $3.8^{*}$ & 0 & 3.8 & 2.6 & - & $\mathrm{t}$ \\
\hline 20 & $3.7^{*}$ & 0 & 3.7 & 2.5 & - & $\mathrm{t}$ \\
\hline 21 & 3.6 & 0 & 3.6 & 2.4 & - & $\mathrm{t}$ \\
\hline 22 & 3.5 & 0 & 3.5 & 2.4 & - & $t$ \\
\hline 23 & 3.4 & 0 & 3.4 & 2.3 & - & $t$ \\
\hline 24 & 3.3 & 0 & 3.3 & 2.2 & - & $t$ \\
\hline 25 & 3.0 & 0 & 3.0 & 2.0 & - & $t$ \\
\hline 26 & 2.9 & 0 & 2.9 & 2.0 & - & $t$ \\
\hline 27 & 2.9 & 0 & 2.9 & 2.0 & - & $t$ \\
\hline 28 & 2.7 & 0 & 2.7 & 1.8 & - & $t$ \\
\hline 29 & 2.7 & 0 & 2.7 & 1.8 & - & $t$ \\
\hline 30 & 2.6 & 0 & 2.6 & 1.7 & - & $t$ \\
\hline 31 & 2.5 & 0 & 2.5 & 1.6 & - & $t$ \\
\hline 32 & 2.4 & 0 & 2.4 & 1.6 & - & $\mathrm{t}$ \\
\hline 33 & 2.3 & 0 & 2.3 & 1.5 & - & $t$ \\
\hline 34 & 2.2 & 0 & 2.2 & 1.5 & - & $t$ \\
\hline 35 & 2.1 & 0 & 2.1 & 1.4 & - & $\mathrm{t}$ \\
\hline 36 & 2.0 & 0 & 2.0 & 1.4 & - & $\mathrm{t}$ \\
\hline 37 & 1.9 & 0 & 1.9 & 1.3 & - & $\mathrm{t}$ \\
\hline
\end{tabular}

* With a secondary constriction. Each value is the mean of 14 metaphase complements in six different plants. 
was unpaired. The long arm of the submetacentric chromosome was shorter than the largest telocentric chromosome (No. 2). As in the female plants the secondary constriction was observed in a pair of middle-sized chromosomes of the male plants.

\section{Fluorescent banding patterns of somatic chromosomes}

When somatic chromosomes at metaphase were stained with the fluorochrome CMA after the treatment with distamycin A, two CMA-bands fluoresced brightly with yellow color at the proximally interstitial region, i.e. at the secondary constriction, of the pair of middle-sized telocentric chromosomes (the 10th pair) in both female (Fig. 4A) and male (Fig. 4C). When the fluorochrome DAPI was used for the chromosome banding, many bright DAPI-bands appeared on the proximal regions of about two-third the large telocentric chromosomes in the complement (Fig. 4B, D). However, no DAPI-band appeared on 12 small telocentric chromosomes (Fig. 5). The submetacentric chromosome specific to the male plants had no DAPI-band (Fig. 5B). The segments fluoresced with CMA were negatively stained.
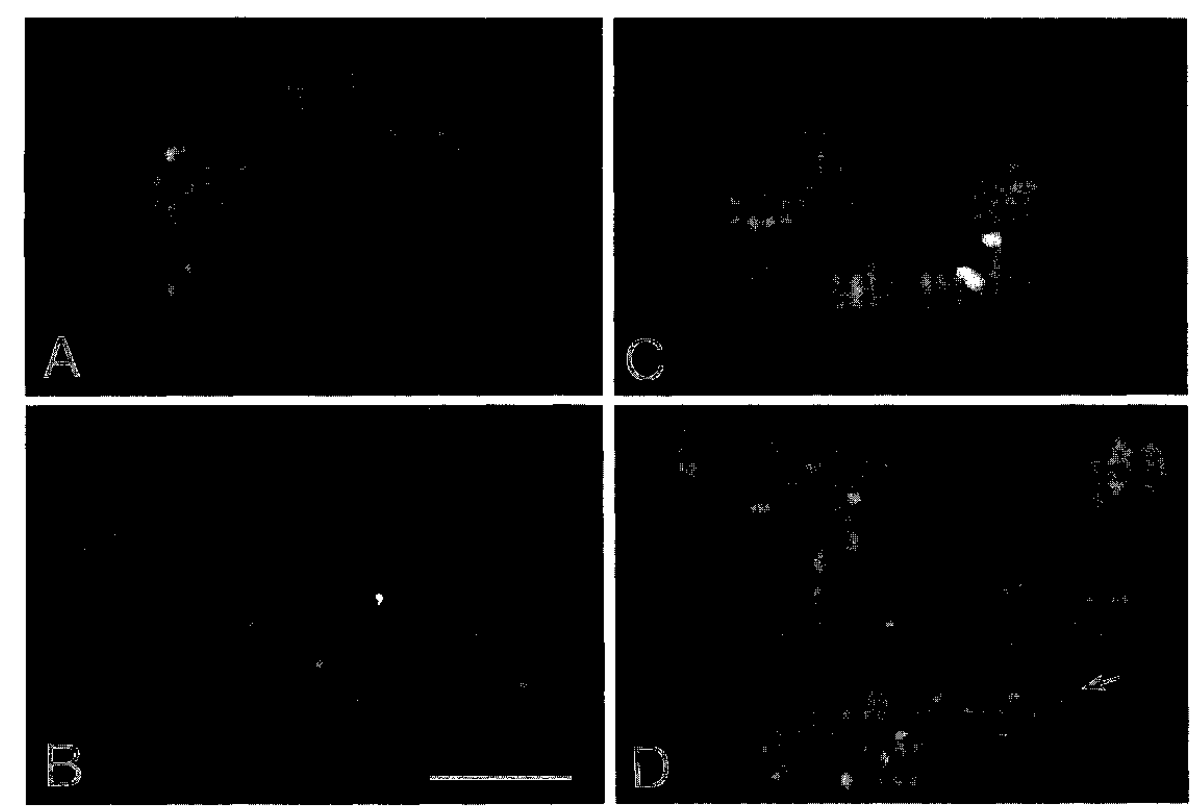

Fig. 4. Metaphase chromosomes of $P$. macrophyllus stained by a fluorescent banding method. A; stained with CMA in a female plant, B; stained with DAPI in female plant, C; stained with CMA in a male plant, D; stained with DAPI in a male plant. Arrow points the submetacentric chromosome. Bar represents $10 \mu \mathrm{m}$. 


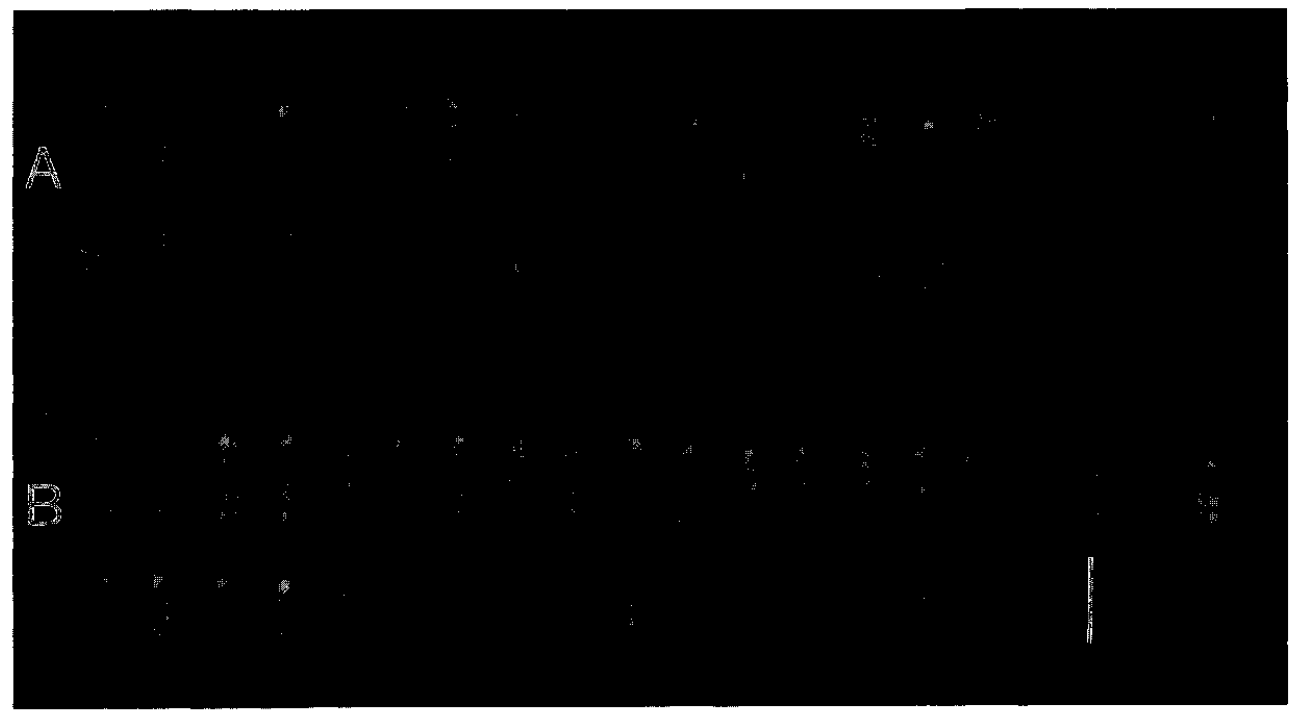

Fig. 5. Metaphase chromosomes of $P$. macrophyllus, stained with DAPI, were arranged in the order of length. A; in a female plant, $B$; in a male plant. Bar represents $5 \mu \mathrm{m}$.

\section{Meiosis in pollen mother cells}

Meiosis was observed in PMCs of male strobili in Podocarpus macrophyllus in mid May. At meiotic prophase the chromosomes condensed not differentially but synchronously. The meiotic chromosomes at metaphase I constantly performed 18 chromosome associates; seventeen bivalents and one trivalent (Fig. 6). The
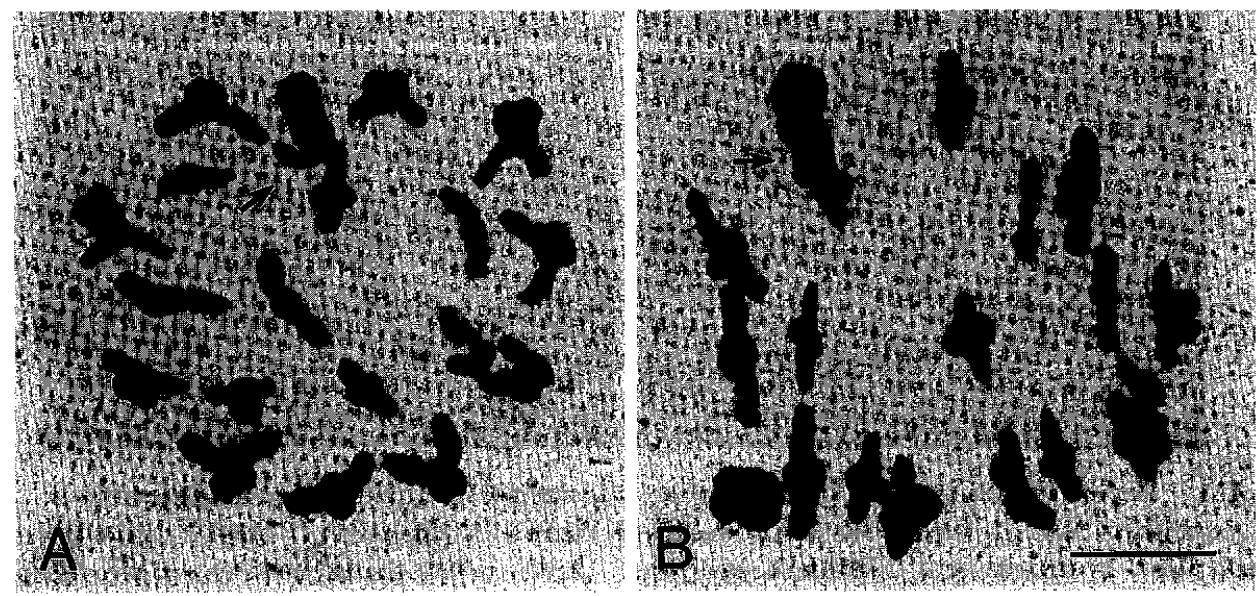

Fig. 6. Meiotic chromosomes at metaphase I in PMCs of $P$. macrophyllus. Seventeen bivalents and one trivalent (arrows) appeared. A; in a male plant (accession number Ehime-26), B; in a male plant (accession number Kyoto-1). Bar represents $10 \mu \mathrm{m}$. 
trivalent was formed by the largest submetacentric chromosome and two telocentric chromosomes, and showed a conspicuous shape with an unpaired free end of the larger telocentric chromosome. Since the larger telocentric chromosome of the trivalent was longer than the long arm of the submetacentric chromosome, it could be identified as the largest telocentric chromosome (No. 2). However, it was not determined that the free end was either proximal or distal end. One or two chiasmata were observed mostly at interstitial regions of the bivalents and the trivalent. The meiotic chromosomes segregated at anaphase I into $n=18$ and 19 (Fig. 7). A chromosome set $(n=19)$ contained 19 telocentric chromosomes, while the other set $(n=18)$ contained a large submetacentric chromosome and 17 telocentric chromosomes. Therefore, the trivalent chromosome was separated into a large submetacentric chromosome and two telocentric chromosomes. At meiotic anaphase II all chromosomes were normally separated to form two types of microspores.
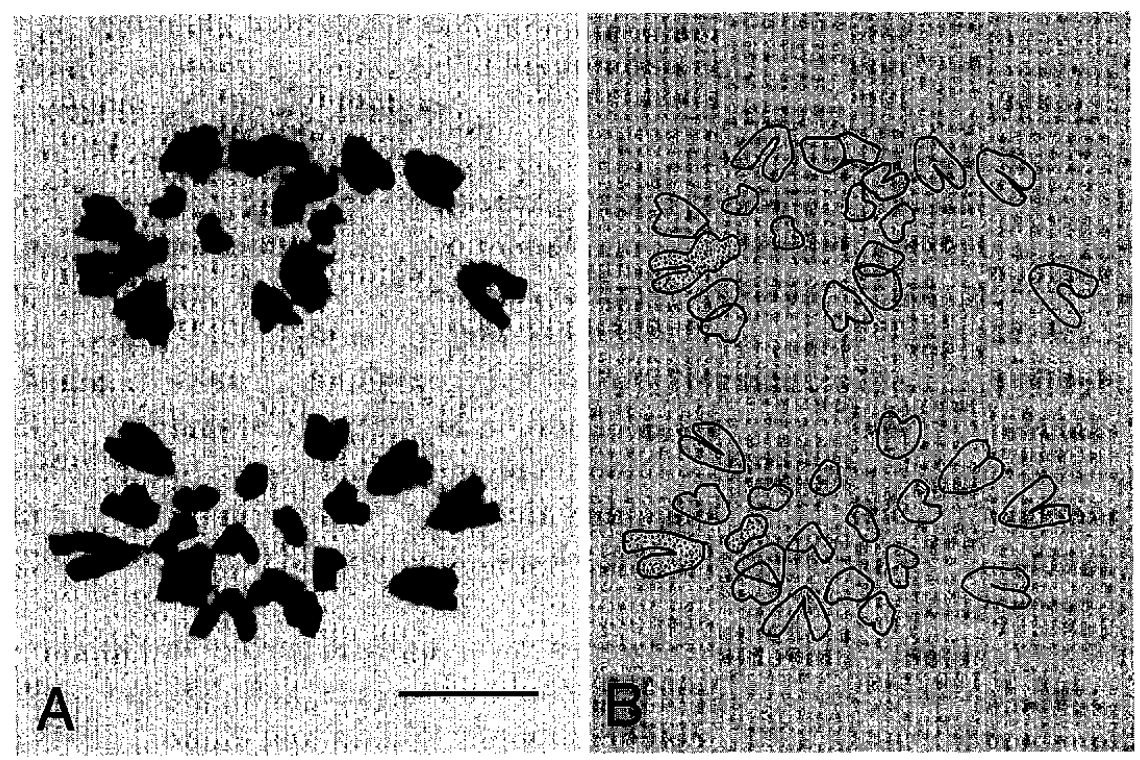

Fig. 7. Chromosome segregation at anaphase I in PMC of $P$. macrophyllus. A; photograph, B; drawing of interpretation. Dotted chromosomes drawn in $\mathrm{B}$ represent sex chromosomes. The upper group of segregated chromosomes was $n=18$, and the lower group, $n=19$. Bar represents $10 \mu \mathrm{m}$.

\section{DISCUSSION}

The present study revealed that the male plants examined had $2 n=37$ chromosomes, and their chromosome complement was composed of one large submetacentric chromosome and 36 telocentric chromosomes. The telocentric chromosomes with a similar size as the long arm of the submetacentric chromo- 
some always had a proximal DAPI-band, while the submetacentric chromosome had no DAPI-band. Hence, the submetacentric chromosome can not be an artifact formed by an association of two telocentric chromosomes. These facts confirmed the presence of large submetacentric chromosomes and the chromosome number of $2 n=37$ in the male plants.

The behavior of meiotic chromosomes observed and the constant chromosome number of $2 n=37$ in male and $2 n=38$ in female suggested that a sex of $P$. macrophyllus could be determined by the sex chromosomes. Since the chromosomes were heteromorphic in male, the chromosomal system of sex determination could be the XXY type; the largest submetacentric chromosome observed only in the male plant could be a $\mathrm{Y}$ chromosome, and two and four telocentric chromosomes could be $\mathrm{X}$ chromosomes in male and female, respectively. The larger $\mathrm{X}$ chromosomes may be called " $\mathrm{X}_{1}$ chromosome" and the smaller ones " $\mathrm{X}_{2}$ chromosome". The $\mathrm{X}_{1}$ chromosome was longer than the long arm of $\mathrm{Y}$ chromosome in pairing of sex chromosomes at metaphase I. Thus, the largest telocentric chromosome (No. 1 and 2 in female, and No. 2 in male) was identified as the $\mathrm{X}_{1}$ chromosome (see Table 3). One of the small telocentric chromosomes in the male plants and two in the female plants could be theoretically the $\mathrm{X}_{2}$ chromosomes, but were not practically identified.

Hair and Beuzenberg (1958) studied chromosomes in many species of Podocarpus and speculated chromosome evolution by centromeric fusion (unequal interchange). They found heterozygous karyotypes in several species of section Eupodocarpus such as $P$. longefoliatalus and $P$. elatus, and stated that the interspecific and intraspecific variation of karyotypes was a transitional stage of chromosome evolution. However, they completely disregarded sexuality. Thus, similarity in karyotypic variation found in $P$. longefoliatalus, $P$. elatus and $P$. macrophyllus might be nothing more than that reflected similarity in the sex chromosomes. The chromosomes of both male and female plants in these species should be examined.

In the gymnosperm sex chromosomes have been reported in Ginkgo biloba (Lee, 1954; Pollock, 1957), Cycas pectinata (Abraham and Mathew, 1962), C. revoluta (Segawa et al., 1971), Ephedra foliata (Mehra and Khitha, 1981) and so on. These papers suggested that chromosome satellites could be involved in sex determination and a XY type of sex determination mechanism could be present in those species. Thus, Podocarpus macrophyllus is the first example of the XXY type of sex determination in the gymnosperm.

The authors wish to express their sincere thanks to Dr. R. Tanaka, Hiroshima University for his valuable suggestions, Dr. K. Kondo, Hiroshima University for critical reading and suggestions, Dr. Y. Kuroki, Ehime University for valuable discussion and Mr. M. Yokota, Ryukyu University for collecting materials from Okinawa Pref. 


\section{REFERENCES}

Abraham, A. and Mathew, P. M. (1962) Cytological studies in the cycads: sex chromosomes in Cycas. Ann. Bot. 26, 261-266.

FloRIN, R. (1963) The distribution of conifer and taxad genera time and space. Acta Horti Bergiani 20, 121-312.

FLORY, W. S. (1936) Chromosome numbers and phylogeny in the gymnosperms. J. Armold Arbor. $17,83-89$.

HaIR, J. B. and Beuzenberg, E. J. (1958) Chromosomal evolution in the Podocarpaceae. Nature $181,1584-1586$.

HAYASHI, Y. (1960) Taxonomical and phytogeographycal study of Japanese conifers. Norin Shuppan, Tokyo, pp. 202. (in Japanese).

Kondo, T. and Hizume, M. (1982) Banding for chromosomes of Cryptomeria japonica D. Don. $J$. Jpm. For. Soc. 64, 356-358.

LEE, C. L. (1954) Sex chromosomes in Ginkgo biloba. Amer. J. Bot. 41, 545-549.

MeHRA, P. N. and KнIтнA, S. C. (1981) Karyotype and mechanism of sex determination in Ephedra foliata Boiss. - A dioecious gymnosperm. Cytologia 46, 173-181.

Mehra, P. N. and Khoshoo, T. N. (1956) Cytology of conifers II. J. Genet. 54, 181-185.

PoLLOCK, E. G. (1957) The sex chromosomes of the maidenhair tree. J. Hered. 48, 290-294.

SEGaWA, M., Kishi, S. and Tatsuno, S. (1971) Sex chromosomes of Cycas revoluta. Jpn. J. Genet. 46, 33-39.

Tahara, M. (1941) Embryogeny of Podocarpus macrophyllus and Podocarpus nagi. Sci. Rep. Tohoku Imp. Univ., Ser. VI, 16, 91-98. 